\title{
Cooperação Estratégica em Inteligência Formação da Defesa Regional: uma Contribuição dos Serviços de Inteligência
}

\author{
Fábio Pereira Ribeiro *
}

Resumo: A produção de informações em um Estado moderno é uma atividade tão antiga como a própria formação do Estado. Esta atividade é conhecida como inteligência, ou produção estratégica de informações para a tomada de decisão do Chefe-de-Estado. A decisão está centrada nas questões de políticas públicas, de política externa, defesa nacional, economia e segurança às ameaças externas ao Estado. Nesta questão, a atividade de inteligência do Brasil pode ser ampliada através de uma sistemática de cooperação da atividade com outros Estados, e para a questão do Mercosul com a Argentina. Nesta relação, a atividade tem um potencial de formação de uma defesa regional e ampliação das questões econômicas, através da construção e troca de conhecimentos estratégicos para o bem comum do Mercosul.

Palavras-chave: Cooperação Estratégica, Inteligência Estratégica, Serviços de Inteligência, Serviços Secretos, Defesa Nacional.

Abstract: The production of information in a modern State is a so old activity as the proper formation of the State. This activity is known as intelligence, or strategical production of information for the taking of decision of Chief-of-State. The decision is centered in the questions of public politics, of external, prohibited politics national, economy and security to the external threats to the State. In this question, the activity of intelligence of Brazil can be extended through a systematics of cooperation of the activity with other States, and for the question of the Mercosul with Argentina. In this relation, the activity has a potential of formation of a regional defense and magnifying of the economic questions, through the construction and exchange of strategical knowledge for the common good of the Mercosul.

Keywords: Strategical Cooperation, Strategical Intelligence, Intelligence Services, Secret Services, National Defense.

\footnotetext{
* Administrador de Empresas, Oficial do Exército Brasileiro, Especialista em Política Internacional e Inteligência Estratégica, Mestre em Administração, Coordenador do Curso de Administração da UNIMONTE, Professor de Relações Internacionais e Administração Estratégica da UNIMONTE e Professor de Inteligência e Contra-Inteligência da FECAP. E-mail: fabiomkt@uol.com.br. Recebido em 16/03/06 e aceito em 05/06/06.
} 


\section{Introdução}

A atividade de inteligência é por si, um dos instrumentos mais estratégicos que a direção de um Estado tem em seu rol de atividades. Ela é por natureza o instrumento que favorece a constituição de poderes com a construção de cenários com o menor risco no processo de decisão de um dirigente nas diversas questóes de Estado.

Nestecontexto, aatividadedeinteligêncianoEstadomodernoérepresentada pelas chamadas agências de inteligência, ou serviços de inteligência, ou também serviços secretos, que representam agências governamentais que têm a responsabilidade de produzir informaçôes estratégicas para a decisão do Chefe-de Estado, organizadas em uma estrutura de coleta, análise e disseminação de informaçóes relevantes ao processo de decisão estratégica do Estado. Estas informaçóes estão vinculadas diretamente ao processo de políticas públicas, política externa, defesa nacional e provimento da ordem pública.

A atividade é vinculada na história diretamente com os contextos de espionagem entre os Estados, mas sempre foi um instrumento fundamental na produção de informaçóes e conhecimentos estratégicos em relação a posição de supremacia de um Estado sobre o outro.

A atividade é desenvolvida a partir de um pressuposto de ação de um Estado sobre as questóes estratégicas de sua sociedade, com objetivos claros de posição e inserção internacional, e ao mesmo tempo na construção de um parâmetro de segurança de Estado, além de defesa contra ameaças externas, mas a atividade é ampliada no contexto exterior em função de coleta de informaçóes para construção de cenários competitivos de participação do Estado, em relação ao mercado externo, sua posição e percepção de valor, imagem sólida e concreta de estabilidade, e de posicionamento de sua soberania perante as grandes potências, além da relação diplomática e propagandista do Estado perante os organismos internacionais.

O seu conceito de atividade é descrito por Herman (1996) como um sistema seqüencial de trabalho, desenvolvido em partes de coleta, segundo fontes e meios, obtenção de informações para análise estratégica e parâmetros de modelos para a construção de cenários, e um ciclo de disseminação da inteligência produzida para os tomadores de decisão.

Conforme Cepik (2003) os sistemas de inteligência (agências) consistem 
em "organizaçóes permanentes e atividades especializadas em coleta, análise e disseminação de informaçóes sobre problemas e alvos relevantes para a política externa”. Nesta visão o processo alimenta um elo forte de desenvolvimento da política pública na amplitude das relaçóes internacionais, pois os alvos das atividades são os Estados, em relação às problemáticas e variáveis que constituem o processo de decisão na política internacional.

$\mathrm{Na}$ construção natural da atividade, a linha diretiva da mesma está ligada intimamente na formação de um processo natural de fontes de informaçóes estratégicas e ao mesmo tempo na linha de vinculo de alimentação de um sistema complexo de informaçóes para a decisáo do processo estratégico. Assim, a amplitude do sistema é alimentada em relação aos vínculos de cooperação para a produção de informaçóes estratégicas, e ao mesmo tempo na troca de informaçóes em relação aos interesses em comum.

A análise da atividade de inteligência a partir de um pressuposto de cooperação é uma linha de formação de um conceito vinculado ao processo básico de integração dos Estados na vertente das Relaçóes Internacionais, objetivando assim um aspecto de construção de uma temática comum entre os Estados.

O estudo apresenta um principio da atividade de inteligência em relação ao Estado Brasileiro de potencializaçáo de sua atividade em relação a outro Estado na América do Sul. O objetivo do trabalho é analisar um parâmetro de cooperação das atividades de inteligência desenvolvidas no Mercosul, principalmente em relação ao Estado Argentino, como eixo de relação na construção de cenários estratégicos nas questóes de defesa nacional, economia e segurança.

O presente estudo aborda um contexto de complexidade do rol de defesa nacional. $\mathrm{O}$ estabelecimento de uma estrutura de inteligência integrada para a formação de um sistema de cooperação em inteligência estratégica. A integração regional é de suma importância para o desenvolvimento dos processos de defesa regional e ao mesmo tempo do fortalecimento dos estados em funçáo da nova ordem internacional e da conquista de uma posição efetiva perante a comunidade internacional. Neste aspecto a informação é um bem vital para o desenvolvimento da integração e neste aspecto, poderá ser o instrumento que fortalecerá todo arcabouço de defesa necessário para a segurança regional e o estabelecimento de forças de aspectos militares, econômicos, financeiros e sociais. Nesta abordagem, o que se espera é uma visão futura de como 
os serviços de inteligência poderiam otimizar suas tarefas, e efetivamente constituírem um sistema integrado de inteligência nacional, onde poderá ser constituído em um modelo regional de inteligência, seguindo padróes de formação de inteligência como na Europa e na Ásia. O estabelecimento deste ensaio é de como os serviços de inteligência da América do Sul, mais precisamente do Brasil e da Argentina, poderiam constituir uma zona de força e poder através do uso eficaz dos sistemas de inteligência no padrão de cooperação? O presente trabalho é um ensaio com pesquisa bibliográfica e acompanhamento das evoluçóes e tendências das teorias de inteligência e os aspectos de potencialização da estrutura e do conhecimento produzido para a defesa nacional e para os estudos estratégicos de cada nação, no enfoque o Brasil e a Argentina.

\section{Cooperação estratégica}

O princípio da cooperação visa o processo de integração onde, dois ou mais agentes possam buscar um pleno desenvolvimento comum, com o intuito de desenvolver capacidades estratégicas para o bem comum.

Nesse sentido, a cooperação estratégica para a região, assim o Mercosul e a América do Sul, visam o princípio da integração das forças e das características que fundamentam a formação de um bloco de força para a conquista de uma posição estratégica internacional.

Conforme Costa (2003, p. 181) "a cooperação sul-americana deve ser vista como um instrumento de alavancagem coletivo de todos os países da região". A força da cooperação traz vantagens para todos os agentes da região, favorece consideraçóes estratégicas na ampla defesa dos interesses regionais.

Esta estrutura de cooperação muitas vezes depende da estrutura do fluxo de informaçóes estratégicas e da forma como as colaboraçóes das capacidades estão estruturadas em função dos princípios estratégicos que norteiam os interesses nacionais e regionais.

A cooperação é força vital para o processo de desenvolvimento estratégico das Naçóes, pois as mesmas têm necessidades específicas que podem ser atendidas conforme a produção de seus parceiros estratégicos.

A cooperação pode favorecer os interesses regionais e principalmente os individuais dos agentes envolvidos, e no processo evolutivo das questóes da globalização, os interesses de desenvolvimento econômico, de defesa, 
energia e de meio ambiente, formam o rol de interesses necessários para a cooperação.

Este rol estabelece condiçóes e norteiam os agentes no desenvolvimento das características e instrumentos da cooperação. Neste aspecto, pode-se imaginar um complexo de instrumentos e organizaçóes que favoreçam os princípios da multiplicidade de interesses em função de um macro interesse regional.

Segundo Melo (2003, p. 159) a cooperação, por conseguinte a regionalização, onde os "países se unem em torno de objetivos comuns, a fim de potencializar a capacidade de atingi-los e maximizar a competitividade econômica global, sempre numa política de bloco", essa assim definida em um princípio de hegemonia regional, onde no aspecto deste estudo o Brasil e Argentina efetivam as forças regionais e geram condiçóes para o fortalecimento de uma estrutura de defesa e informação, que possam favorecer as estruturas de competitividade e segurança internacional.

Neste aspecto a cooperação pode ser potencializada através de instrumentos que favoreçam a constituição de uma estrutura de informações integradas para a formação de estratégias que visam os interesses nacionais e regionais. Para o aspecto distinto os interesses de Brasil e Argentina e, por conseguinte os interesses do Mercosul.

Nesse sentido, os interesses nacionais formam o poder nacional de cada país envolvido, onde os princípios de cooperação favoreceriam os princípios de integração regional, onde Brasil e Argentina seriam os agentes norteadores do processo estratégico e de desenvolvimento regional para estabelecimento da posição de fortalecimento internacional.

Desse modo, o poder nacional, segundo Hage (2004, p. 55) "se expressaria na uniáo de vários elementos, recursos humanos, econômicos e geográficos, cada um sendo um tipo de interesse nacional”. Assim, o poder nacional seria fator preponderante no processo de desenvolvimento regional, em função dos interesses particulares de cada estrutura de poder nacional, além da formação impar dos interesses em mérito das relações internacionais.

A constituição deste poder nacional deve ser evidenciada através de um principio de constituição dos valores das informaçóes estratégicas, onde o processo de cooperação poderá favorecer a formação de estruturas vitais para o desenvolvimento estratégico de cada Nação dentro da estrutura regional.

$\mathrm{O}$ poder nacional e a cooperação são fatores que podem neutralizar 
problemas como o do poder concentrado de países do $1^{\circ}$ mundo e da hegemonia de poder contra estruturas de terror, que possam interferir em estruturas estratégicas para justificar problemas do terrorismo, como na tríplice-fronteira e nas questóes de segurança do porto de Santos em São Paulo no Brasil, em relação ao ISPSCODE.

A percepção estratégica leva a um princípio de força de cooperação da informação estratégica, onde a estrutura de Estados, Brasil e Argentina, podem fortalecer o aspecto de desenvolvimento regional, da América do Sul, com uma estrutura integrada de cooperação de Inteligência Estratégica.

A cooperação da Inteligência Estratégica é um instrumento histórico do desenvolvimento das relaçóes internacionais, muitas vezes utilizada na guerra, mas como fundamento estrutura das relaçóes entre os povos, onde um dos principais teóricos das relaçóes internacionais define como "a única maneira conhecida de reduzir as incertezas” (DUROSELLE, 2000, p. 117).

Esta estrutura visa um aprofundamento do que pode ser estratégico para a regiáo e o que defende efetivamente o interesse particular de cada país. O que pode ser estratégico está intimamente ligado à nova ordem internacional, que após o 11 de setembro, o mundo viu uma nova direção estratégica, voltada para a defesa militar em relação ao terrorismo, e a região do Mercosul, muitas vezes colocada em "xeque" em função de seus interesses particulares.

E esta análise favorece um a um conceito de política de defesa e desenvolvimento regional através de uma estrutura conjunta de Inteligência Estratégica, onde o principio norteador pode ser desenvolvido através de uma estrutura de cooperação dos serviços de inteligência, ou dos sistemas de inteligência de cada agente envolvido no processo, para o caso em estudo, a ampliação de forças no caso do Brasil e da Argentina.

A cooperação do processo de inteligência já é definida por um dos maiores expoentes científicos da área como um fator chave de sucesso regional nos aspectos de defesa e de integração econômica. Segundo Herman (1996, p. 217) "modern intelligence is a multinacional activity. National intelligence power is a function not only of national capabilities but also of the foreign cooperation and product they obtain".

E a estrutura de cooperação de inteligência favorece a constituição de uma posição estratégica frente à nova ordem internacional, onde a estrutura de defesa nacional sofre impacto imediato em virtude da posição de força que os Estados Unidos da América (EUA) impóem. 
A condição da estrutura de cooperação de inteligência direciona os aspectos estratégicos de uma Nação no caminho da inserção internacional, e neste aspecto a estrutura relacionada entre Brasil e Argentina pode favorecer um estabelecimento concreto em relação ao Mercosul e a América do Sul, favorecendo ainda a concretização de posição da América Latina.

A cooperação estabelece direções, no aspecto da inteligência, para distinçóes que formam as agendas externas para os Ministérios da Defesa, sendo o narcotráfico e o terrorismo, que a partir dos acontecimentos de 11 de setembro de 2001, tiveram um crescimento vertiginoso na pauta de segurança internacional.

A preocupaçáo para este estudo e para um potencial direcionamento estratégico nas agendas é a cooperação dos países nas trocas de informaçóes correspondentes aos interesses de cada supra-regiáo, e dos aspectos que possam gerar valor estratégico para o desenvolvimento regional e a inserção internacional.

Neste mérito, o processo de integração pode auxiliar a constituição séria de um conjunto de atributos para o desenvolvimento final da inserção e da defesa, onde conforme Waltz (2002, p. 147) "num sistema de auto-ajuda cada uma das unidades gasta uma porção do seu esforço, não a perseguir o seu próprio bem, mas a arranjar os meios de se proteger dos outros".

A preocupaçáo para o processo é a visão realista que permeia o sistema internacional através da sistemática de liderança da força desenvolvida pelo EUA. Assim, Waltz (2002, p. 149-150) descreve:

Num ambiente desorganizado o incentivo de cada unidade é pôr-se numa posição de ser capaz de tomar conta de si mesma, uma vez que não pode contar com mais ninguém para fazê-lo. O imperativo internacional é "toma conta de ti mesmo". Alguns líderes de nações podem entender que o bem-estar de todas elas poderia aumentar através da sua participação numa completa divisáo do trabalho.

Já que a visão realista pode trazer conseqüências sérias de desestabilização, o processo de cooperação poderá neutralizar as chamadas novas ameaças, principalmente nas questóes relacionadas ao Mercosul e a América do Sul, tomando como base os seus principais representantes, o Brasil e a Argentina. 
Este processo de cooperação, que pode ser estendido para o processo de inteligência, pode ser analisado a partir da visão de equilíbrio de poder regional no estudo do Programa Paz e Segurança nas Américas, onde é sistematizado um esforço de segurança cooperativa, que nesse sentido pode ser abordado conforme Rojas F. apud López (2003, p. 78) "como um sistema de interaçóes estatais que, coordenando políticas governamentais, previne e contém as ameaças aos interesses nacionais e evita que as percepçóes que delas têm os estados se transformem em tensóes, crises ou confrontaçóes abertas".

E para esta condição, López (2003, p. 78) condiciona em áreas de cooperação, sendo elas:

1)Prevenção de crises e manutenção do status quo;

2)Modernização e equilíbrios regionais;

3)Medidas de confiança mútua;

4)Controle e limitação de armamentos;

5)Desarmamento.

E nesse sentido de ampliação para a cooperação do processo de defesa e integração regional, o mesmo autor (2003, p. 79) esclarece em termos de instrumentos de desenvolvimento da cooperação, sendo assim:

A transparência - vale dizer, o fluxo de informação entre os Estados cooperados - as medidas de confiança mútua e a dissuasão, agora sim, entre os sócios, cujo alicerce deve estar constituído pelos dois procedimentos anteriores e não pela mera acumulaçáo unilateral de meios e pela manutençáo do temor, da desconfiança e do segredo dos desígnios próprios, por parte dos cooperantes.

A cooperação é ampliada principalmente para atender a necessidades específicas de cada país, mas que de uma forma integrada aflige a região em função das novas ameaças, onde López (2003, p. 83), descreve como o terrorismo internacional, a narcoatividade, o tráfico ilegal de armas, a degradação do meio ambiente, o fundamentalismo religioso, as migraçóes internacionais, a pobreza, o crime organizado e em separado a bio-pirataria.

Estas ameaças dão condiçóes para a estruturação de um sistema de 
inteligência de cooperação, onde o intercâmbio de informaçóes e posiçóes pode estabelecer uma posiçáo de defesa em conforto com as relaçóes de inserção internacional, que os países da região necessitam, frente às novas vertentes da ordem internacional, tomando como base inclusive a vertente realista.

Além desta estrutura percebe-se um pensamento avançado da vertente que a cooperação pode levar a uma estrutura ampliada de competitividade para a região, além da defesa. Conforme Diamint (2001, p. 73):

La seguridad de las naciones se sostiene crecientemente a través de una voluntad manifesta de Estados enfrentados o con intereses contrapuestos para alcanzar acuerdos comprehensivos que incluyan dentro de la defensa nacional temas de comercio, desarrollo, cuidado del medio ambiente y libertad de mercado. La dualidad se presenta entre la necesidad de los Estados de aceptar los desafíos a la competitividad económica en un mundo que funciona como un mercado global y la aparición de conflictos no tradicionales que son percibidos como una amenaza a la seguridad común y para los cuales se espera contar con fuerzas armadas adaptables y flexibles.

Em uma abordagem completa, a estrutura de cooperação traz efetivamente uma possibilidade de defesa e competitividade perante outros blocos regionais. Neste sentido, o esforço do Brasil em uma ação combinatória com a Argentina, poderá fortalecer este sentido. Rousseau (2003, p. LIX) já definia que "as combinaçóes de Estados que possam surgir tendem a ser competitivas”. Em uma nova estrutura realista, a cooperação fortalece pressupostos estratégicos para o desenvolvimento regional. Este estabelecimento depende do fluxo e da troca de informaçóes estratégicas, que direcionam e formam o conjunto de interesses nacionais, que podem inter-relacionar com interesses da região.

Assim, a cooperação é um instrumento de cunho estratégico para a definição de horizonte para a inserção internacional, claro que estabelecido os parâmetros para o seu desenvolvimento. Neste, estudo a base é a inteligência estratégica e seus instrumentos de uso, sistematizado em uma estrutura integrada de inteligência, no caso entre Brasil e Argentina. 


\section{Inteligência e cooperação estratégica}

A atividade de inteligência é intimamente ligada ao contexto estratégico de cada Nação. Para o princípio em estudo, a atividade é uma ligação para a formação de um arcabouço de conhecimento de fortalecimento regional de inserção internacional dos países que formam a região.

Nesse aspecto, os serviços de inteligência da América do Sul passam por diversas análises para modificaçóes de suas estruturas que possam estabelecer um sistema efetivo de informaçóes, incluindo um controle institucional do Estado.

E nesse aspecto é importante ressaltar a estrutura de inteligência em função dos problemas, ameaças e necessidades conjuntas dos Estados que formam a Região. Neste aspecto Spotta (2002, p. 149) que pelo aparecimento de problemas interdependentes, a estrutura pode ser estabelecida de forma cooperada:

El surgimiento de problemas interdependientes que no pueden ser solucionados conforme a las práticas habituales dentro de la jurisdicción del Estado y de sus instituciones diplomáticas, como ser: la polución ambiental, las crisis monetarias, el tráfico de drogas, el terrorismo, las epidemias - entre ellas el SIDA - y el flujo de refugiados. Estos nuevos problemas llevan a la población a dudar acerca de la capacidad de sus estados para solucionar las crisis, la inducen a reestructurar su sistema de lealtades al tiempo que hacen crecer la noción de que la cooperación internacional es esencial para la política mundial, dando nacimiento a un vasto rango de asociaciones transnacionales que se sitúan como nuevos desafíos a la autoridad de los estados.

Esta atividade integra definitivamente a estrutura de informaçóes necessárias para o desempenho efetivo dos estados nas problemáticas mundiais, que afligem a região de forma complexa, onde muitas vezes colocam as posiçóes dos países inseridos regionalmente em uma posição negativa perante a comunidade internacional. Um caso em especial, o de células terroristas na tríplice fronteira.

O quesito da integração para cooperação, dos serviços de inteligência já é um ponto de discussão dentro da comunidade de informaçóes, onde Spotta 
(2002, p. 154) afirma que "paradójicamente la interrelación de los organismos de inteligência es una necessidad largamente proclamada pero poças veces llevada a la práctica".

Após o 11 de setembro de 2001, a estrutura integrada de inteligência foi proclamada como um dos novos direcionamentos estratégicos dos estados e das regióes (blocos), até mesmo para justificar a caça ao terror imposta pelos EUA. Esta imposição pode estabelecer excessos, mas isto não pode direcionar a uma problemática de estruturaçáo de serviço cooperado de inteligência, e deve se ter uma preocupação latente do estado com estas questóes, pois segundo Vizentini (2004, p. 129):

Depois de 11/9, a expressão terrorismo passou a integrar a linguagem cotidiana em todo o mundo. Contudo trata-se de um termo empregado de forma ampla e inadequada, com fortes conotaçóes políticas. Assim, tem sido objeto de manipulação, para justificar uma nova agenda internacional.

Esta questão deve ser uma preocupação efetiva no pensamento da estrutura de cooperação dos serviços de inteligência, mas ao mesmo tempo para a região da América do Sul, a questão é uma pauta constante dos processos de informaçóes estratégicas.

Mas efetivamente, o grande pensamento estratégico na visão das relaçóes internacionais para o desenvolvimento da região, que pode ser ampliado pelo uso efetivo dos serviços de inteligência, é a integração regional e a recuperação do Mercosul, onde segundo Vizentini (2004, p. 155):

A grande batalha, contudo, é a integração sul-americana, objetivo prioritário do governo. Recuperar o Mercosul e associa-lo à Comunidade Andina são o objetivo estratégico, base da inserção internacional do país, e a alternativa viável à integração hemisférica projetada pela ALCA. Da mesma forma, a cooperação nos campos diplomático, científico, militar e econômico com os grandes países em desenvolvimento - como Rússia, China, Índia e África do Sul - é uma condição indispensável para o país tornar-se um dos pólos de poder num sistema mundial multipolar e membro permanente do Conselho de Segurança da ONU. 
A grande razão da integração e cooperação dos serviços de inteligência é a potencialização da estrutura de informaçóes que possam criar um sistema efetivo de defesa regional, e fortalecer a estrutura competitiva de cada país envolvido no processo. Segundo Herman (1996, p. 204) "one basic reason for cooperation is that there is always more information potentially available than any agency can collect by itself”. A própria estrutura de inteligência favorece ao estabelecimento de uma política exterior (HERMAN, 1996, p. 213) integrada em fundamento com as necessidades da região e do fortalecimento do bloco (Mercosul).

O fortalecimento da região, também é derivado de um progresso nas políticas de defesa nacional, e a inteligência, conforme Antunes (2002, p. 197) "é um instrumento de poder do Estado e tem como objetivo a busca de eficácia na condução da política de defesa nacional [...]”. Este instrumento pode ser potencializado para a região, constituindo assim uma estrutura integrada de defesa, onde já existem exercícios conjuntos das Forças Armadas, agora a necessidade explicita do processo de informaçóes.

Esta integração de serviços é importante para a constituição inclusive, de modelos de inteligência, ou de atuação, que muitas vezes estão constituídos de forma integrada para atender as necessidades de cada regiáo e suas potenciais ameaças.

Segundo Cepik (2003, p. 112-113), pode se destacar para uma visão mais abrangente de modelos que geram sistemas nacionais de inteligência:

-Um modelo "europeu continental" caracterizado por média centralização da autoridade sobre as unidades do sistema, média integração analítica dos produtos de inteligência, alto envolvimento da atividade de inteligência com as instâncias de policymaking e, finalmente, uma baixa efetividade dos mecanismos de accountability e supervisão (oversight);

-Um modelo "asiático", caracterizado por baixa centralização da autoridade sobre as unidades do sistema, alta integraçáo analítica dos produtos de inteligência, médio envolvimento da atividade de inteligência com as instâncias de policymaking e, de forma ainda mais pronunciada do que no tipo continental, uma baixa efetividade dos mecanismos de accountability e supervisão. 
Mas para o principio da cooperação, a estrutura deve ser institucionalizada através de um ciclo de inteligência ligado ao contexto do policymaking e da accountability.

A preocupação dos estudos estratégicos neste século XXI é o aprofundamento da Defesa e da Integraçáo, motes para este encontro. Por isso, a estrutura de inteligência integrada na região poderá fortalecer a partir de um sistema que integre os sistemas de inteligência de cada país, formando uma estrutura de informaçóes coligadas com as vertentes diplomáticas de cada Estado, e respeitando o controle institucional de cada Nação. A integração para a defesa, estabelece inclusive parâmetros para a atividade de inteligência, onde o foco principal para a questão está na configuração das novas ameaças. E nesse sentido, uma estrutura de inteligência integrada fortalece os parâmetros para a condução de políticas de defesa nacional que culminam em uma política de defesa regional e internacional.

O que se pensa é o fortalecimento da estrutura já existente para a região, e a condição do Brasil e sua integração através do Mercosul com a Argentina, poderá favorecer este aspecto, incluindo a posição de força na região para a inserção internacional. Neste aspecto, a atividade assegura um estabelecimento integrado de proteção e de segurança internacional, ampliado do conceito de segurança nacional.

A integração poderá trazer benefícios do tipo:

- fortalecimento do ciclo de inteligência regional contra as ameaças latentes e a integração das informaçóes estratégicas comuns aos Presidentes das Repúblicas;

- intercâmbio de analistas e profissionais de inteligência para o conhecimento das culturas e práticas para a conduçáo de um processo de inteligência regional;

- estabelecimento de uma escola integrada de inteligência, que visa atender as necessidades do complexo exterior e da política internacional de cada estado;

- integração dos sistemas de inteligência nacional de cada estado, em combate às ameaças junto à segurança internacional;

- estabelecimento de um controle integrado da atividade, juntamente ligada ao processo de defesa da regiáo, de forma institucionalizada;

- criação de um banco de informaçóes, que congrega todas as fontes e 
potencialidades de inteligência para a estruturação de políticas de segurança e defesa regional;

- fortalecimento da inteligência militar e geração de conhecimento para o complexo de defesa da América do Sul, além do fortalecimento da integração e cooperação das Forças Armadas da região;

- dotação de uma força conjunta de inteligência integrada ao sistema internacional de polícia, que possa estabelecer um banco de informaçóes completo e em tempo real do crime organizado internacional;

- gerar uma estrutura de informaçóes estratégicas que possa estabelecer parâmetros para o desenvolvimento de estratégias nacionais e conjuntas, onde cada governo possa aproveitar suas potencialidades através de um sistema de fortalecimento do Mercosul, através de Inteligência Econômica, Inteligência Financeira e Inteligência Estratégica.

Este rol de elementos que favorecem o processo de integração, é um fator que potencializa e direciona os estudos de inteligência para o nível de cooperação, preconizado de longa data por Herman (1996).

Brasil e Argentina não estão mais preocupados com o uso da força, mas sim efetivamente em criar um ambiente de defesa regional, onde suas estruturas de estado possam desenvolver processos de ampliação de suas democracias e de seu desenvolvimento econômico e social. A atividade de inteligência e a cooperação dos processos podem efetivamente constituir uma saída para o processo de integração e fortalecer os princípios tão defendidos pelos dois países, o do Estado Democrático de Direito.

\section{Considerações finais}

Quando se pensou no estudo dos serviços de inteligência, uma preocupação latente é o processo de como um serviço pode auxiliar na constituição de uma estrutura de defesa regional? E como efetivamente ele pode auxiliar na construção de uma estrutura de informaçóes estratégicas para o Brasil e a Argentina, como base solidificada para a região e para o Mercosul.

A preocupação é o estabelecimento estratégico de fatores de cooperação, principalmente para minimizar os efeitos negativos das novas ameaças que criam uma sombra sobre a América do Sul. Neste aspecto, a atividade de inteligência de estado poderá interferir diretamente nestas questóes e gerar frutos de defesa, além de integrar efetivamente a força na região. 
Além dos aspectos de defesa, é importante destacar, que a atividade de inteligência poderá fortalecer o desenvolvimento nuclear, o desenvolvimento científico, o desenvolvimento educacional e também o social, através de estruturas de intercâmbio de informaçóes que possam favorecer a criação de políticas públicas de melhoria, além do intercâmbio das melhores práticas de cada país que formam a região.

A atividade de inteligência já é bem discutida entre Brasil e Argentina, além dos controles institucionais da atividade, o que se pensa neste momento é fortalecer a discussão de defesa com a estrutura coletiva e de cooperação dos serviços de inteligência e dos sistemas nacionais de inteligência, fortalecendo assim Estado, Política e Polícia, além das Forças Armadas.

Esta mesma estrutura poderá estabelecer uma força regional que dará suporte e pensamento estratégico para a inserção internacional, além da constituição de uma camada de proteção contra as ameaças latentes da nova ordem internacional, principalmente o estabelecimento de açóes terroristas e a ampliação do narcotráfico.

Os governos já direcionam para esta vertente, principalmente na preocupação da cooperação de defesa regional.

Este estudo tem por finalidade abrir a discussão da amplitude da temática de inteligência de Estado, principalmente na questão de integração de forças entre os Estados que formam o desenvolvimento de uma comunidade da América do Sul. 


\section{Referências Bibliográficas}

ANTUNES, Priscila Carlos Brandão. SNI \& ABIN - uma leitura da atuação dos serviços secretos brasileiros ao longo do século XX. Rio de Janeiro: FGV, 2002.

CEPIK, Marco A. C. Espionagem e democracia. Rio de Janeiro: FGV, 2003.

COSTA, Darc. Estratégia nacional. Rio de Janeiro: L\&PM, 2003.

DIAMINT, Rut. Democracia y seguridad en América Latina. Buenos Aires: Nuevohacer, 2001.

DUROSELLE, Jean-Baptiste. Todo império perecerá. Brasília: UNB, 2000.

HAGE, José Alexandre A. As relaçōes diplomáticas entre Argentina e Brasil no Mercosul. Curitiba: Juruá, 2004.

HERMAN, Michael. Intelligence power in peace and war. New York: 1996.

LOPEZ, Ernesto Justo. Nova problemática de segurança e novas ameaças. In: MATHIAS, Suzeley Kalil; SOARES, Samuel Alves (Org.). Novas ameaças: dimensões e perspectivas. São Paulo: Sicurezza, 2003.

MELO, Andrea Sabbaga de Melo. Regionalização e globalização - fenômenos simultâneos. In: CARVALHO, Leonardo Arquimimo de; NETO, Francisco Quintanilha Véras; LIXA, Ivone F. Morcilo. Politica internacional, politica externa \& relaçôes internacionais. Curitiba: Juruá, 2003. p. 159-170.

OLIVEIRA, Odete Maria de et al (Org.). Relaçôes internacionais. Ijuí: Unijuí, 2003.

ROUSSEAU, Jean-Jacques. Rousseau e as relaçôes internacionais. São Paulo: Imprensa Oficial, 2003.

SPOTTA, Angel Hermán Lapieza. La multiplicidad de actores internacionales y la inteligencia estratégica. Nueva Inteligencia, Buenos Aires, ENI-SI, v. 1, n. 2, p. 147-154, 2002.

VIZENTINI, Paulo Fagundes. O descompasso entre as naçóes. Rio de Janeiro: Record, 2004.

WALTZ, Kenneth N. Teoria das relaçôes internacionais. Lisboa: Gradiva, 2002. 